\title{
El problema metafísico de Hegel (De la conciencia al saber absoluto)
}

Jaime Rivas Castillo

Plantear el problema metafísico de Hegel basándose en la interpretación que hace Xavier Zubiri en Los Problemas fundamentales de la metafísica occidental (PFMO) implica por lo menos dos cosas, para efectos de estas líneas. Primero, que se seguirá el punto de partida y el esquema propuesto por el filósofo vasco en la obra señalada, lo cual exigiría mantener fidelidad, en la medida de lo posible, al esquema zubiriano durante la marcha del problema en su conjunto. Esta exigencia plantea, a su vez, una dificultad metodológica que hay que resaltar; y es que Zubiri sintetiza en unas cuantas páginas todo el proyecto hegeliano - $\mathrm{o}$, si se prefiere, todo el sistema- cuando pudo haber profundizado en alguna cuestión fundamental - lo cual no fue seguramente su intención. El riesgo que se corría era simplificar en demasía algunas cuestiones que bien pudieron profundizarse en atención a la importancia de las mismas en el conjunto del sistema hegeliano. De ahí que surja la siguiente implicación.

Segundo, dado que, de acuerdo al esquema propuesto en Los problemas fundamentales... son tres los pasos para explicar la marcha de la cuestión metafísica de Hegel, en estas líneas se considerará - para ahondar en la riqueza de este punto- el primero de ellos, es decir, el que pretende dar cuenta de la índole de la razón y que está planteado en la Fenomenología del Espiritu de Hegel. Así, para abordar el problema ya acotado, se utilizará además otro texto zubiriano que nos arroja

El problema metorisico de Hegel (de lo conciencio al sober absoluto) 
oportunas luces, a saber: "Hegel y el problema metafísico", escrito en 1931 y que forma parte de las conferencias recogidas en el libro Naturaleza, historia, Dios (NHD), publicado en 1944. Ello, tomando en cuenta que ambas obras - PFMO y NHD - están separadas por treinta y cinco años de labor filosófica de Zubiri. Asimismo, cuando el caso lo requiera, se incluirán otras referencias bibliográficas que contribuyan a un mejor tratamiento del problema y aclaren con mayor precisión las respuestas. Finalmente, este texto tiene como propósito no sólo recoger la original interpretación de Zubiri, sino articular otros puntos de vista, para tomarle la palabra a Hegel en su desarrollo y plasmar así lo que de esencial tiene que ofrecernos.

Con todo, debe dejarse claro desde el principio que el problema que aquí nos ocupa ha sido objeto de sendos estudios en una gran cantidad de bibliografía e interpretaciones - no por ello del todo disponibles. Conociendo la orientación metafísica de Zubiri en el conjunto de Los Problemas fundamentales... es comprensible que quiera explorar el pensamiento mismo de Hegel, dejando por sentada la textura interna de su problema metafísico. De ahí que penetre hasta lo más radical de Hegel que, como este mismo lo afirma, es la idea de lo absoluto en donde se "unifican" naturaleza y espíritu, sujeto y objeto, acto de conocimiento y cosa conocida, que las filosofías anteriores a Hegel habian separado infranqueablemente. En suma, de la mano de Zubiri, las presentes líneas tienen como propósito plantearse el problema metafísico de Hegel y, habiendo hecho esto, desarrollar la marcha de la cuestión, hasta llegar a la respuesta que nos dará el mismo Hegel.

\section{Planteamiento del problema}

Zubiri se plantea la cuestión metafísica de Hegel en la obra citada de una manera que, aunque muy sintética, no deja de ser original. Por eso, cabe mencionar que Los Problemas fundamentales... ha sido escrito en plena madurez del filósofo vasco. Brevemente, Zubiri instala intelectual e históricamente a Hegel en lo que ha dado por llamar "horizonte de la nihilidad" o de la creacionalidad, propia del pensamiento cristiano occidental. Zubiri sostiene que "lo que Hegel ve en el horizonte de la Creación es la unidad de Dios y las cosas"' y, seguidamente, equipara este horizonte al absoluto. En consonancia con lo anterior, si otros autores como Descartes ven en dicho horizonte la incertidumbre o, Santo Tomás, la finitud intrínseca del ente, a 
Hegel no se le revela nada, sino que ese horizonte mismo es lo formalmente absoluto (das Absolute). Pero el absoluto, siendo principio y resultado, es entonces el Todo, surgiendo en este momento la tarea filosófica de Hegel: la razón debe aprehender ese todo en su verdad. Por tanto, la filosofía debe ser una aprehensión racional del todo; pero la verdad es el todo y el todo es la verdad. De ahí que el problema entero de Hegel sea esa aprehensión del todo en su verdad racional.

Adicionalmente, en "Hegel y el problema metafísico" Zubiri amplía el punto de partida hegeliano. En efecto, Hegel se considera él mismo, en la historia de la filosofía occidental, la máxima expresión filosófica o la madurez de la metafísica que emprendió su camino desde Parménides y que llegaba hasta Schelling. Luego de hacer un breve recorrido de la historia de la metafísica, de Aristóteles a Schelling, pasando por Descartes y Kant, Zubiri ubica el punto de partida de Hegel en la unificación de la naturaleza con el espíritu. Es el mismo problema que, para autores como E. Bloch, es el fundamental en Hegel: la mediación dialéctica entre sujeto y objeto. ${ }^{2}$ A lo largo de la historia de la filosofía, los filósofos se habían inclinado hacia uno u otro término; pero Hegel quiere, de alguna manera, integrar ambos términos, sin que por esa "unificación" dejen de ser lo que son. Volveremos sobre ello. Este proyecto de "unificación" queda esbozado y descrito en la Fenomenología del Espiritu, primera gran obra sistemática de Hegel; pero alcanza un mejor desarrollo en la segunda magna obra hegeliana, es decir, la Ciencia de la lógica (Wissenschaft der Logik).

Siguiendo el esquema de Los problemas fundamentales... habría que recorrer primero el camino de la conciencia a la Ciencia o al Saber absoluto, que es la tarea misma de la Fenomenología y así responder a una pregunta fundamental: ¿qué entiende Hegel por razón?, es decir, eso hacia lo cual apunta la estructura misma de lo absoluto, del todo. Aunque el problema entero para Zubiri implique otras dos preguntas - ¿cuál es la estructura misma de esa razón? y icómo es la razón principio de las cosas? - el desarrollo de estas líneas se centrará en la primera de las interrogantes, atendiendo a que el despliegue de la Fenomenología misma -o sea del espíritu en la consecución de la Ciencia (Wissenschaft) - implique un mayor detenimiento en cada uno de sus momentos. 


\section{De la conciencia al Saber absoluto}

Antes de empezar la marcha del problema hay que insistir en algunas observaciones de carácter introductorio. En primer lugar, Hegel se ha propuesto - siguiendo de alguna manera las pretensiones de Kant-convertir el filosofar en algo "científico", es decir, su tarea filosófica estará orientada hacia la consecución de un fin que para el caso es la Ciencia, el Saber absoluto. El atributo "absoluto" garantiza que la Ciencia sea el Todo, y no el saber parcial de las ciencias desarrolladas a lo largo de los siglos XVIII y XIX. Hegel tiene una profunda confianza en el alcance de la razón humana. ${ }^{3}$ En otras palabras, el filósofo -y sólo el filósofo- debe devenir Sabio (Sage), o sea, el hombre satisfecho por lo que es y por lo que sabe. Pero el Sabio, además, debe aspirar a la Sabiduría hasta identificarse con ella misma, describiendo perfectamente el Ser (Sein) por medio del Discurso. Precisamente por ello, toda la trama de la Fenomenologia del Espíritu es la marcha de la conciencia hacia la Ciencia (Wissenschaft), o el Saber absoluto.

En segundo lugar, el conjunto de la Fenomenologia puede ser dividido en dos grandes "totalidades parciales" : la Conciencia del Espíritu (Cap. I-VI) y la Autoconciencia del Espíritu (Cap. VII). El capítulo VIII de la Fenomenología está consagrado al Saber absoluto en el que se da la reconciliación de las dos subdivisiones anteriores. Como quiera que sea, para que Hegel diga qué es la razón, deberá responder a otras tres preguntas. $1^{\circ}$, ¿qué es la verdad de lo absoluto?; $2^{\circ}$, ¿qué es la razón que posee esa verdad?; y, $3^{\circ}$, ¿cómo se llega a ese concepto de razón?.

\subsection{La verdad de lo absoluto}

En primer lugar, equé es la verdad del absoluto o la verdad del todo? La respuesta podría ser sencilla, en apariencia. Bastaría con inclinarse o bien por el sujeto cognoscente o por el objeto conocido, según las teorías del conocimiento tradicionales. De hecho, la filosofía tradicional ha tomado estos derroteros; es decir, por un lado está la cosa conocida, el absoluto y, por otro, está el sujeto cognoscente, el acto de conocimiento o la razón. Nos enfrentamos pues al problema sujeto-objeto en Hegel que gravita a lo largo de la Fenomenologia del Espiritu. Sin embargo, la respuesta de Hegel a este problema es clara: no existe tal dualismo que escinde el sujeto con el objeto. En otras palabras, la oposición entre sujeto y objeto es falsa. 
Dicha oposición es falsa porque Hegel, fiel a su estilo "unificantereconciliador", niega de plano la existencia empírica y separada del sujeto y del objeto. Afirmar tal cosa sería simplemente una abstracción sin sentido, propia del "sabio vulgar" anterior al mismo Hegel en la historia (las concepciones idealistas o subjetivistas). Como sostiene A. Kojeve, "el Sujeto y el Objeto, tomados aisladamente, son abstracciones que no tienen "realidad objetiva" (Wirklichkeit) ni «existencia empírica" (dasein). Lo que existe en realidad, desde el momento que se trata de la Realidad-de-la-cual-se-babla; y puesto que en verdad hablamos de la realidad, no puede tratarse para nosotros más que de una Realidad-de-la-cual-se-habla... lo que en realidad allí existe es el Sujeto-que-conoce-el-objeto o, lo que es igual, el Objeto-conocido-porel-Sujeto"5. Esta frase es ya un preámbulo de la resolución del problema: en Hegel se opera una unificación del sujeto y el objeto que Kojeve explica con la relación: "sujeto-que-conoce-el-objeto" y "objeto-conocido-por-el-sujeto".

Si afirmamos que a lo largo de la historia de la filosofía ha habido dos grandes períodos anteriores a Hegel, que Zubiri mismo señala en Naturaleza, historia, Dios (el de la preponderancia del objeto o Naturaleza $^{6}$ y el de la preponderancia del sujeto o Espíritu ${ }^{7}$ ), en y por Hegel emerge un tercer período que "se puede caracterizar como una trascendencia recíproca de sujeto y objeto: ambos términos no son más que la expresión... de la unidad fundamental por la que el hombre sólo existe como sujeto-en-el-mundo, comprometido en un proceso de libertad que conlleva su propia traducción (una traducción "reflexionante») en el mundo de la objetividad" . Por tanto, el mismo Hegel reconoce a su manera que él ha dicho la última palabra — siendo el que ha alcanzado la Ciencia - sobre la cuestión, al haber unificado en y por el Espíritu Absoluto al sujeto con el objeto. Hegel supera toda concepción dualista del Hombre y de la Naturaleza, del Sujeto y del Objeto, del en si y para sí, en una concepción unitaria del Absoluto.

Zubiri, explicando a Hegel, echa por tierra el dualismo sujeto-objeto hablando en términos similares. Primero, porque, en palabras de Zubiri, "ningún acto de conocimiento...está estructurado por ese dualismo", ya que a la verdad no sólo le compete la cosa, el objeto, sino el saber que el sujeto tiene de ella. Por tanto, la verdad es, "a una", cosa y saber. Segundo, cuando el objeto de conocimiento es el mismo absoluto pueden darse dos posturas equivocadas: a) que el sujeto crea

El proble na metafisico de Hegel (de la conciencia al saber absoluto) 
tener un instrumento para conocer el absoluto y entonces la razón que cree extraer la verdad del absoluto sólo aprehende lo que este instrumento elaboró del absoluto, lo cual no es el absoluto; b) que la razón sería el medio o la luz por el que el sujeto conoce el absoluto, y entonces la razón sólo conocería esa luz y no el absoluto. De ahí que, siguiendo a Hegel, no pueda tomarse como punto de partida tal escisión entre razón y absoluto, sino ambas "a una".

Entonces se confirma la convicción hegeliana que niega tal hiato. Habrá que decir, consecuentemente, que el absoluto es su propia verdad, es decir, que sólo lo verdadero es absoluto. En Hegel, pues, el sujeto y el objeto, la cosa y el saber que se tiene de ella constituyen una unidad radical. Pero dicha unidad no sólo consiste en un mero nexo copulativo; no se trata de una simple identidad formal entre la cosa y el saber que se tiene de ella; o, lo que es lo mismo, no es una identidad formal entre naturaleza y espíritu. Para Hegel, —señala Zubiri- hay algo que es fundamento de esa pertenencia de ambos términos: ese fundamento es el Todo, es el absoluto, el en sí y para sí. ${ }^{10}$

Quizás ha sido J. Findlay uno de los estudiosos de Hegel que más ha insistido en la exigencia mutua de la naturaleza y del espíritu, y sus palabras le sonarán familiares al mismo Zubiri. El mundo natural viene a ser la exigencia inmediata del espíritu; es decir, de alguna manera, lo dado es una condición necesaria para la consecución de la Verdad en la Ciencia. Entonces, "el Espíritu, el principio de unidad y universalidad, sólo puede comprender plenamente el mundo cuando lo mira meramente como el material para su propia actividad, como opaco a esa actividad sólo en la medida en que esa opacidad es una condición necesaria para el proceso de hacer transparente el mundo. Y no puede encontrar satisfacción completa en ningún otro modo de considerar el mundo... el Espíritu encuentra finalmente que la parcial satisfacción que logra al ver el mundo desde perspectivas alternativas, se derrumba ante el examen y envuelve su pensamiento en conflicto y en frustración intelectual. Mientras que en la comprensión de sí mismo en Espíritu, como la "verdad» de todo, reúne y armoniza todos esos otros modos parciales de comprender el mundo"."

Hegel concluye pues que la verdad es cosa y saber, "lo verdadero no es el resultado... sino el todo; aquello que vincula el resultado a su principio"12 ; es la unificación vital de la naturaleza con el espíritu. Por tanto, la respuesta a la pregunta inicial será que la verdad no es sim- 
plemente una verdad "de" lo absoluto, "sino que es lo absolutamente verdadero, la verdad en su índole absoluta"."13

\subsection{La razón de la verdad}

Ahora surge la pregunta, ¿qué es la razón que posee esa verdad? A este punto, Zubiri complica la cuestión; y partiendo de la "unificación" de la cosa y del saber que se tenga de esa cosa llega a afirmar que la razón es "a una razón de la identidad de la cosa y razón de mi saber sobre ella"'4. Hegel examina la cuestión por ambos términos del conocimiento: por parte del absoluto (objeto de conocimiento) y por parte de las certezas y saberes ciertos respecto a ese absoluto (que residen en el sujeto cognoscente). Ambos términos convergerán en la idea de concepto hegeliano.

Por el lado de las certezas, éstas son verdaderas cuando responden, en su estructura interna, al concepto que se tenga de lo que debe ser verdadero. Por parte de las cosas, decimos que poseemos la verdad absoluta de algo cuando ese algo responde efectivamente a su propia esencia, es decir, a su concepto. Por tanto, el resultado es la intrínseca unidad entre la certeza y la verdad (la realidad de la cosa) en el concepto. O, si se prefiere, "la estructura formal de la verdad como absoluto es el concepto". ${ }^{15}$ Este resultado lleva a Hegel a afirmar que el concepto es la identidad de la certeza y la verdad. En definitiva, no se trata pues de la razón "de" lo absoluto, sino de "la" razón absoluta, en respuesta a la identidad unitaria operada por el concepto. Dicho en otros términos, la razón es toda la realidad, es "a una" el concepto de la cosa y la verdad cierta sobre esa cosa.

Ahora habrá que hacerle a Hegel dos preguntas: $1^{\circ}$ iqué entiende por concepto?, $2^{\circ}$ ¿qué entiende por es cuando dice que el concepto "es" lo absoluto y la realidad? En primer lugar - apunta Zubiri-, para Hegel, concepto no es la idea de representación o segunda presentación intelectual de algo que ya se presentó una vez. Tampoco es la doble idea de concepto de los medievales: no es el "concepto objetivo", es decir, el que todos los hombres tienen de algo; ni es el "concepto formal" o el acto en el que la mente concibe conceptos objetivos. Según Zubiri, Hegel habla "de los dos [tipos de concepto] a una" $^{16}$, (das begreiffendes Denken) que Zubiri traduce como pensar concipiente: aquel que toma el concepto objetivo en tanto que emergiendo del acto mismo de concebir (concepto formal); o, en otros 
términos, lo objetivo saliendo de lo formal. Por tanto, el concepto no es algo muerto, sino que está dotado de vida, es una "unidad vital"17. La razón es pues la vida del concepto, lo cual nos lleva a la segunda pregunta.

En segundo lugar, qué significa que el concepto sea lo absoluto y la realidad. Si el concepto es una "unidad vital", entonces debe producir algo. Hegel afirma que lo concreto resulta de la vida interna de los conceptos. Para llegar a ello, opera una inversión en la primariedad de los términos de un juicio cualquiera $(\mathrm{S} \text { es } \mathrm{P})^{18}$, según la lógica tradicional. De acuerdo a esta inversión, el sujeto es lo que es gracias a que el predicado lo determina en sus caracteres internos. Es lo que Hegel llama "proposición especulativa", en contraposición a la "proposición lógica" tradicional. Es el predicado pues este constituye al sujeto, y no al revés. Pero además, no es simplemente que el sujeto esté bajo (sub) el predicado, sino que encuentra su conformación misma desde el predicado. De ahí que Hegel sostenga con seguridad que lo concreto esté constituido por la vida interna de los conceptos y el sujeto sea el resultado del predicado. Entonces, la verdad será siempre lo general, el todo y la razón es lo absolutamente verdadero, la vida interna del concepto.

En definitiva, siendo la razón la vida del concepto, éste envuelve y unifica, por esa vitalidad que le es propia, la realidad y la certeza de las cosas.

\subsection{El camino hacia el concepto de razón}

Para llegar a la razón, que es la vida del concepto, Hegel parte de la conciencia (Bewusstsein). Según Zubiri, en Hegel conciencia significa darse cuenta de algo. Conciencia es el saber en tanto que darse cuenta de, o un saber sin más implícito (en sí) en el orden de la razón (que posee un saber explícito - para sí). Hegel no sólo separa la conciencia de la razón (en contra de Descartes), sino que la escinde radicalmente como en ambos extremos del camino hacia la consecución de la Ciencia. Al nivel de conciencia, la verdad sólo aparece como fenómeno (fainesthai). En este momento, la conciencia se somete a una experiencia (Erfabrung) de la que Zubiri se pregunta por su objeto, por la forma de esa experiencia y por su proceso. Pero antes de abordar estas tres cuestiones (objeto, forma y proceso de la experiencia) habrá que precisar más la noción de conciencia en Hegel. 
Tomándola como el darse cuenta de lo dado, lo que está ahí, el punto de partida es la certeza sensible (Sensación) en la que se da una especie de "conocimiento implícito, [que] para transformarse en conocimiento explícito debe pasar a ser conciencia perceptiva, en la cual el objeto que se nos enfrenta dejará de ser un mero "ése» y pasará a ser una cosa, caracterizada por distintos universales o propiedades". ${ }^{19}$ El momento primero de la certeza sensible es el momento de la Identidad en el que no hay relación alguna con otros "esos"; es el momento de la inmediatez, indiferenciación y fugacidad, del particular, del "algo", privado de toda relación. Luego, la certeza sensible exige a la conciencia perceptiva (Percepción), la cual "se desmorona a su vez y falla en sus pretensiones de darnos a conocer una realidad absoluta" 20 . En este momento, lo particular de la certeza sensible se ha determinado, es una "cosa", un ser especificado. Pero es además el momento de la ilusión en el que la cosa es aparentemente "esta cosa", pero que es idéntica a sí misma y se contradice -por su momento inherente de contradicción interna. Después aparece el entendimiento cientifico (Entendimiento) que postula entidades inobservables "para explicar los fenómenos que nos son ofrecidos por los sentidos" y que tiene frente a sí un objeto que le aparece como "reflejo".

En resumen, la conciencia es, en palabras de Kojeve, "un todo formado por la sensación de lo particular, por la percepción de lo especifico y por el entendimiento de lo universal; y ese Todo es un movimiento dialéctico que integra las sensaciones particulares especificándolas en las Percepciones que universaliza el Entendimiento, o un movimiento que a la inversa, hace penetrar el Entendimiento universal, especificado por la Percepción, en la particularidad sensible"."2 Aclarado este punto, volvamos al esquema zubiriano. Efectivamente, debemos explorar el objeto, la forma y el proceso de la experiencia que se opera en la conciencia.

Primero, el objeto de la experiencia. De alguna manera Zubiri ya lo ha mencionado: el objeto de la experiencia es hacer una especie de tránsito de un saber "parcial", un saber "acerca de" las cosas que se dan en la conciencia, a un saber "total" o absoluto; es decir, del ser y no del aparecer del saber absoluto, lo cual supone el desarrollo de la misma Fenomenología del Espíritu, en todos sus momentos hasta llegar a la consecución de la Ciencia en donde es superado el dualismo sujeto-objeto.

\section{9}

El problemo metafisico de Hegel (de lo conciencia al saber absoluto) 
Segundo, la forma de la experiencia, que es "formalmente" el mismo desarrollo progresivo de la conciencia hacia la ciencia (Saber absoluto). Es lo que Hegel denomina "dialéctica de la experiencia" (Dialetik der Erfabrung) ${ }^{22}$, que no es más que el mismo proceso dialéctico en el que la conciencia aparece en sus distintos momentos (sensibilidad, percepción y entendimiento) hasta llegar a saberse como tal absoluto -sólo habiendo llegado al estadio de la Autoconciencia (Selbstberousstsein). Zubiri apunta que esta es la dialéctica que aparece en la Ciencia de la Lógica (Wissenschaft der Logik): aquella dialéctica interna y constitutiva de la razón misma y del saber en cuanto tal. Finalmente, Zubiri subraya que esta dialéctica no se refiere a los distintos actos de la conciencia, tomados aisladamente, sino a toda la conciencia tomada como "configuración total" (Gestalt).

Tercero, el proceso de la experiencia de la conciencia, que Zubiri explaya en seis momentos y que es el recorrido mismo de la Fenomenología del Espiritu en sus ocho capítulos. ${ }^{23}$

$1^{\circ} \mathrm{La}$ conciencia (Bewusstsein). Es el punto de partida, sobre el cual ya se ha dicho que es el momento de lo dado en su sensación, percepción y entendimiento. En la conciencia se da una especie de acto de inducción que recoge lo dado en las sensaciones (el objeto que está ahí), interviniendo luego la percepción y finalmente el entendimiento que elabora universales de lo dado. A este nivel pues, la razón no ha aparecido y el saber es, precisamente, darse cuenta de que lo dado "está ahí" con unas determinadas propiedades que lo hacen diferente de otros "algos". Pero ya hay en el entendimiento un cierto nivel de abstracción que se constituirá como tal en el siguiente momento.

$2^{\circ}$ La autoconciencia o conciencia de sí (Selbstbewusstsein) en el que la conciencia, mediante un proceso interno, se vuelve necesariamente sobre sí misma. Aquí no aparecen las cosas, sino sólo mis pensamientos acerca de ellas. Este es el dominio del "yo" con mis pensamientos: ese yo que es tenerse a sí mismo como objeto (para sí); es decir, el mismo yo es el objeto del conocimiento. Acá Zubiri hace una observación muy aguda. $\mathrm{Y}$ es que nos movemos en el ámbito de la identidad entre el "yo" y el objeto, que es en esencia la filosofía de Fichte. Empero, Hegel rompe esa "vana y estéril identidad", puesto que los pensamientos no sólo son míos, y hasta ahí nada más, sino que, de alguna manera, le pertenecen a la cosa misma de la que son 
pensamientos. Y ya hemos visto que la verdad de la cosa debe coincidir con la certeza que de ella tiene la conciencia.

$3^{\circ}$ Unificación de la certeza y de la verdad. Es el aparecimiento de la verdad de la razón (Vernunft) o el aparecer del saber absoluto dentro de la frontera de la autoconciencia. Esta identidad entre la certeza y la verdad de la cosa es lo esencial de la razón. Por tanto, ya nos vamos acercando a la razón absoluta (Ciencia). Pero habrá que dar unos pasos más.

$4^{\circ}$ La razón como tal (Vernunft), en que la unidad de la certeza y la verdad se constituye como una unidad viva, porque verdad y certeza tienen un fundamento que es el todo o lo absoluto.

$5^{\circ} \mathrm{El}$ espíritu (Geist). Siendo la razón la vida interna del concepto, (principio vital) es entonces espíritu. Hasta acá la razón aparece como espíritu; dicho en otros términos, de la conciencia, pasando por la autoconciencia, el saber ya pertenece a la razón misma, a la razón como espíritu, cuyo ser es "actuosidad" (actividad propia). ${ }^{24}$

$6^{\circ} \mathrm{La}$ verdad absoluta. Al final del camino - que a la vez nos remite al inicio y al proceso mismo, es decir al todo (sistema)-, bástenos decir que el espíritu, por su vitalidad interna, se descubre a sí mismo es su forma de saber absoluto. A este nivel, el saber absoluto ya no sólo aparece en la conciencia, sino que es la verdad del todo, del absoluto. Y lo absoluto es el concepto, en el que tiene vida la razón. En definitiva, lo absoluto es espíritu.

\section{Conclusión}

"Todo en su verdad racional" afirmaba Zubiri en el punto de partida. $Y$ es el mismo resultado al que se ha llegado: el absoluto como verdad de la razón. Pero este resultado no podía obtenerse sin recorrer, junto con Hegel, el largo camino de la Fenomenología del espíri$t u$. Sólo al final del camino Hegel puede llegar a identificar el ser con el pensar. "No es pues que el hombre sea y, además, sepa, sino que el ser del hombre es su saber. Y como el saber contiene lo que la cosa es, resulta que, en el momento en que yo sé del ser, soy el ser". ${ }^{25}$

El orden transcendental es para Hegel un sistema de conceptos, de unidades vitales. Es además, un orden principiado, en tanto que su principio es la vida misma del espíritu. La visión del ser y de la realidad parte del pensar concipiente; es decir, de aquél que concibe el ser y la 
realidad, y lo real es lo concebido por la razón. Esta identidad que ocurre en la razón no es la simple equiparación parmenídea de la realidad y el ser, sino que es la constitución misma de lo real de las cosas en tanto que coincide con la certeza misma que la razón tiene de esas cosas.

Esta es la importancia metafísica de Hegel: haber recogido toda la tradición filosófica anterior y articulado sistemáticamente en una unidad radical en que el sujeto y el objeto, la naturaleza y el espíritu no volverán a estar escindidos. Unas y otras filosofías — valga la simplificación en términos de "ismo"- le tomarán la palabra a Hegel: desde el existencialismo pietista de Kierkegaard hasta el materialismo de Marx, pasando por el voluntarismo de Schopenhauer. De ahí que las palabras de Zubiri aún tengan resonancia respecto de la filosofía hegeliana: "toda auténtica filosofía comienza hoy por ser una conversación con Hegel". ${ }^{26}$

\section{Anexo: estructura de la Fenomenología del Espíritu de Hegel}

\section{Estructura general}

PRÓlOGO

\section{CIENCIA DE LA EXPERIENCIA DE LA CONCIENCIA}

\section{A. Conciencia}

I. La certeza sensible o el "esto" y la "suposición"

II. La percepción, o la cosa y la "ilusión"

III. Fuerza y entendimiento, fenómeno y mundo suprasensible

B. Autoconciencia

IV. La verdad de la certeza de sí mismo

A. Independencia y sujeción de la autoconciencia; señorío y servidumbre

B. Libertad de la autoconciencia; estoicismo, escepticismo y la conciencia desventurada

C. AA. Razón

V. Certeza y verdad de la razón

A. Razón observante

B. La realización de la autoconciencia racional por sí misma

C. La individualidad que es para sí real (reell) en y para sí misma 
BB. El Espiritu

VI. El espíritu
A. El espíritu verdadero, la eticidad
B. El espíritu extrañado de sí mismo, la cultura
C. El espíritu cierto de sí mismo, la moralidad

\section{La Religión}

VII.La religión
A. Religión natural
B. La religión del arte
C. La religión revelada

DD. El saber absoluto

VIII. El saber absoluto

\section{Subdivisiones señaladas por Labarrière}

(a) Orden lineal: ocho subdivisiones principales escritas en números romanos y articuladas por el mismo Hegel.

I. La certeza sensible o el "esto" y la "suposición"

II. La percepción, o la cosa y la "ilusión"

III. Fuerza y entendimiento, fenómeno y mundo suprasensible

IV. La verdad de la certeza de sí mismo

V. Certeza y verdad de la razón

VI. El espíritu

VII. La religión

VIII. El saber absoluto

(b) Orden literal: seis subdivisiones estructuradas por Hegel.
(A) Conciencia
(B) Conciencia de sí
(C) (AA) Razón

El problema metafisico de Hegel (de la conciencia al saber absoluto) 
(BB) El Espíritu

(CC) La religión

(DD) El saber absoluto

(c) "Totalidades parciales" (TP): dos grandes articulaciones de la obra que terminan en una "reconciliación de la Conciencia con la Conciencia de sí"." El Saber absoluto define la ecuación de conjunto y da a conocer la unificación de ambas reconciliaciones.

Conciencia del Espíritu (TP 1)
(A) Conciencia
(B) Conciencia de sí
(C) (AA) Razón
(BB) El Espíritu

Conciencia de sí del Espíritu (TP 2)

(CC) La Religión

Saber absoluto (Todo)

\section{Notas}

1. PFMO, p. 249.

2. "Del mismo modo, Hegel supo hacer conocer siempre, una y otra vez, la idea fundamental en la que se hallan implicadas todas sus profundidades y complicaciones. He aquí lo esencial, lo que constantemente palpita en la filosofía hegeliana: la mediación dialéctica sujeto-objeto es, así, indefectible". Crf. Bloch, E. Sujetoobjeto. El pensamiento de Hegel, México, FCE, 1985, p.38.

3. "No obstante, si el temor a equivocarse infunde desconfianza hacia la ciencia, la cual se entrega a su tarea sin semejantes reparos y conoce realmente, no se ve por qué no ha de sentirse, a la inversa, desconfianza hacia esta desconfianza y abrigar la preocupación de que este temor a errar sea ya el error mismo En realidad, este temor presupone como verdad, apoyando en ellos sus reparos y sus consecuencias, no sólo algo, sino incluso mucho que habría que empezar por examinar si es verdad o no. Da por supuestas, en efecto, representaciones acerca del conocimiento como un instrumento y un médium, así como también una diferencia entre noso- 
tros mismos y ese conocimiento; pero, sobre todo, presupone el que lo absoluto se balla de un lado y el conocimiento de otro, como algo para sí y que, separado de lo absoluto es también, indudablemente, fuera de la verdad, es sin embargo verdadero, hipótesis con la que lo que se llama temor a errar se da a conocer más bien como temor a la verdad". Cfr. Hegel, G.W.F. Fenomenologia del Espiritu, México, FCE, 1985, p. 52.

4. La frase es de Labarrière. Cfr. Labarrière, P.J., La Fenomenología del Espíritu de Hegel, México, FCE, 1985, p. 73.

5. Kojève, A., La dialéctica de lo real y la idea de la muerte en Hegel, Buenos Aires, La Pléyade, 1972, p. 13.

6. "Por esto, toda la filosofía griega es ciertamente una pregunta acerca del ser; pero una pregunta acerca del ser, en cuanto su verdad queda descubierta y explicada en un decir, en un saber lo que la cosa es. Por el logos nos sumimos explícitamente en la visión de lo que el universo verdaderamente es". Cfr. NHD, p. 212.

7. "De esta manera, se produce de Descartes a Kant, y muy especialmente de Kant a Schelling, la contraposición frente a la naturaleza de la que nos habla Grecia, de ese otro orden, de ese otro mundo: el mundo del espíritu". Cfr. NHD, p. 214.

8. Labarrière, J.P., La fenomenología del Espíritu... p.17.

9. PFMO, p. 252.

10. NHD, p. 215.

11. Findlay, J.N., Reexamen de Hegel, Barcelona, Grijalbo, S. A. 1969, p. 51.

12. NHD, p. 216.

13. PFMO, p. 254.

14. Ibid, p. 255.

15. Ibid.

16. Ibid, p. 257.

17. Ibid, p. 259.

18. Según la lógica clásica, en un juicio de la forma $S$ es $P$, el sujeto (S) tiene primariedad sobre el predicado (P); es decir, el predicado representa una propiedad que tiene el sujeto.

19. Findlay. J.N., Reexamen...p. 89.

20. Ibid, p. 90.

21. Kojève, A., La Concepción de la antropologia y del ateismo en Hegel...p. 71.

22. PFMO, p. 263.

23. Ver en el anexo la estructura de la Fenomenología del Espiritu en los tres modos de articulación señalados por Labarrière.

24. PFMO, p. 267.

25. NHD, p. 219.

26. Ibid, p. 209.

27. Labarrière, J.P., La fenomenología del Espíritu... p. 69.

\section{BibLIOGRAFÍ CONSULTADA}

- Bloch, E. Sujeto-objeto. El pensamiento de Hegel, México, FCE, 1985.

- Findlay, J.N., Reexamen de Hegel, Barcelona, Grijalbo, S. A., 1969.

- Hegel, G.W.F., Fenomenologia del Espíritu, México, FCE, 1985.

El problemo metoristco de Hegel (de lo conciencio al saber absc:uto) 
- Hegel, G.W.F., Introducción a la bistoria de la filosofía, Madrid, Aguilar, 1975.

- Kojève, A., La Concepción de la antropología y del ateísmo en Hegel, Buenos Aires, La Pléyade, 1972.

- Kojève, A., La dialéctica de lo real y la idea de la muerte en Hegel, Buenos Aires, La Pléyade, 1972

- Labarrière, J.P., La fenomenología del Espíritu de Hegel, México, FCE, 1985.

- Zubiri, Xavier, Naturaleza, historia, Dios, Madrid, Editorial Nacional, 1955.

- Zubiri, Xavier, Problemas fundamentales de la metafísica occidental, Madrid, Alianza Editorial, 1995. 